TERRA. Revista de Desarrollo Local e-ISSN: 2386-9968

Número 8 (2021), 605-627

DOI 10.7203/terra.8.18435

IIDL - Instituto Interuniversitario de Desarrollo Local

\title{
Desarrollo local y vaciamiento demográfico en Moratalla (Murcia, España): ¿un proceso reversible a través de la promoción turística?
}

\author{
Francisco José Morales Yago \\ Universidad Nacional de Educación a Distancia (Madrid, España) \\ fjmorales@geo.uned.es \\ https://orcid.org/0000-0003-0089-6567
}

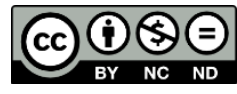

Esta obra se distribuye con la licencia Creative Commons 


\title{
SECCIÓN NOTAS Y AVANCES DE INVESTIGACIÓN
}

\author{
Desarrollo local y vaciamiento demográfico en Moratalla (Murcia, España): ¿un proceso reversible \\ a través de la promoción turística?
}

Resumen: El municipio de Moratalla, ubicado en la comarca del NO de Murcia (España) presenta por sus datos respecto a la evolución poblacional una de las pocas excepciones en el conjunto regional, ya que pierde población desde al menos cuatro décadas. Esta situación significa un progresivo deterioro en la actividad económica, el envejecimiento de la población y un importante abandono del casco histórico de la ciudad, así como en una serie de pedanías localizadas en un amplio término municipal de 954,82 km2, el tercero más extenso de la Región de Murcia que está compuesta por cuarenta y cinco términos municipales. Los análisis estadísticos, cuestionario tabulados y entrevistas de carácter cualitativo a expertos locales señalan un escenario para esta ciudad y su término municipal preocupante, que en caso de que no se consiga frenar podría desembocar a medio y largo plazo en una aguda regresión social y económica de este municipio. A través de la herramienta DAFO aplicada básicamente a la promoción turística de interior se harán propuestas que contribuyan a detener la sangría demográfica, diversificando la económica local basada en el sector primario y en la salida diaria de muchos vecinos a otras localidades, donde desarrollan sus puestos de trabajo.

Palabras clave: Despoblación, vaciamiento, desarrollo local, Moratalla, estrategia territorial.

\section{Local development and demographic emptying in Moratalla (Murcia, Spain): a reversible process through tourist promotion?}

Abstract: The municipality of Moratalla, located in the NW region of Murcia (Spain) presents, due to its data regarding population evolution, one of the few exceptions in the regional set, since it has lost population for at least four decades. This situation means a progressive deterioration in economic activity, the aging of the population and a significant abandonment of the historic center of the city, as well as in a series of districts located in a large municipal area of $954.82 \mathrm{~km} 2$, the third largest of the Murcia Region, which is made up of forty-five municipalities. Statistical analyzes, tabulated questionnaires and qualitative interviews with local experts indicate a worrying scenario for this city and its municipal area, which in the event of failure to stop could lead in the medium and long term into an acute social and economic regression of this municipality. Through the SWOT tool applied basically to inland tourism promotion, proposals will be made that help to stop demographic bleeding, diversifying the local economy based on the primary sector and the daily departure of many residents to other locations, where they develop their jobs of work.

Key words: Depopulation, emptying, local development, Moratalla, territorial strategy.

Recibido: 01 de noviembre de 2020

Devuelto para revisión: 18 de diciembre de 2020

Aceptado: 03 de enero de 2021

Referencia / Citation:

Morales, F. J. (2021). Desarrollo local y vaciamiento demográfico en Moratalla (Murcia, España): ¿un proceso reversible a través de la promoción turística?. TERRA. Revista de Desarrollo Local, (8), 605-627. DOI 10.7203/terra.8.18435 


\section{INTRODUCCIÓN}

El municipio de Moratalla, enclavado en la comarca del NO de Murcia, con una extensión de $954 \mathrm{~km}^{2}$, es el tercero más amplio de los cuarenta y cinco que componen la Comunidad Autónoma de la Región de Murcia. Se trata de un territorio de interior, limítrofe por el Noroeste, Norte, Noreste y Oeste con los respectivos municipios de la provincia de Albacete de Letur, Ferez y Socovos, Hellín y Nerpio; por el Suroeste con el granadino municipio de La Puebla de Don Fadrique y finalmente con los municipios de la misma Región de Murcia de Calasparra, Caravaca de la Cruz y Cehegín al Este, Sur y Sureste respectivamente.

Figura 1. Localización geográfica y configuración por municipios de la comarca del Noroeste Murciano

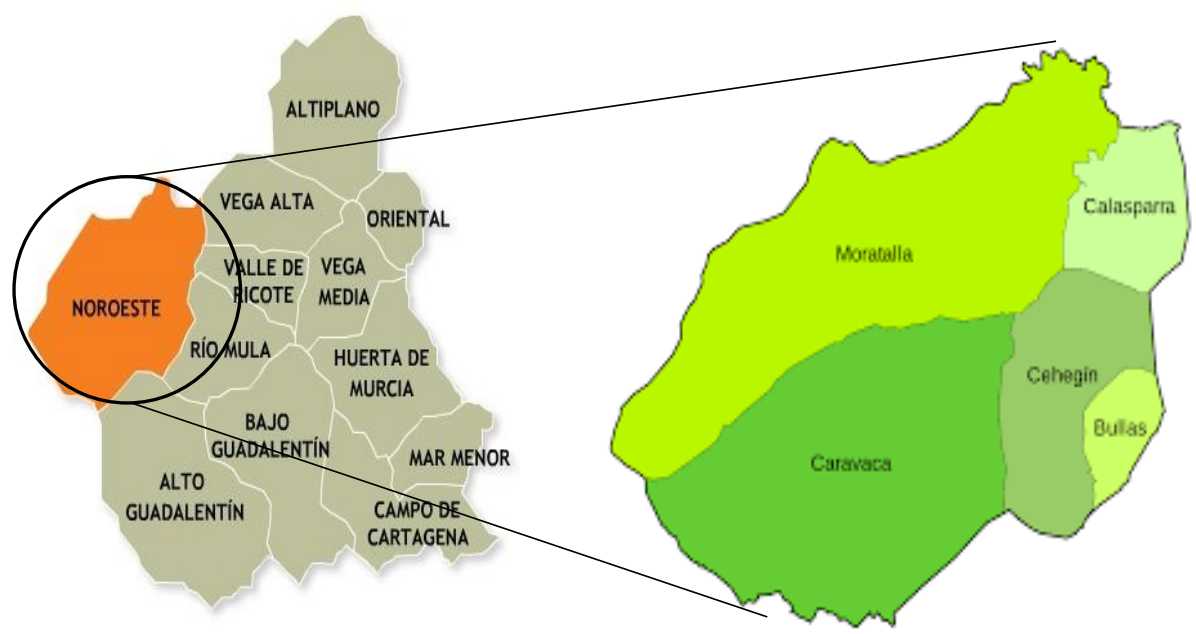

Fuente: Fuente: https://www.regmurcia.com/

Se trata de un conjunto de "tierras altas" en relación al resto de la Región, albergado la máxima altitud de la CC.AA, con el Pico de Revolcadores que alcanza la cota de 2027 metros y una altitud media del término de 633 metros $(\mathrm{m})$ sobre el nivel del mar muy superior a la Regional que alcanza los $219 \mathrm{~m}$. El término municipal se haya localizado dentro del dominio orográfico de la región Subbética (Conesa, 2006) y la característica general es la presencia de montañas y escarpadas cordilleras que se orientan de suroeste a nordeste, con más de veinte crestas que superan la altitud de 1.400, concretamente, algo más del $50 \%$ de la superficie rebasa los $1.000 \mathrm{~m}$, mientras que el resto con los necesarios espacios de transición apenas alcanza los $400 \mathrm{~m}$, por tanto los contrastes son importantes y las pendientes acentuadas, lo que repercute en la existencia de valles de abundante vegetación y pronunciados precipicios muy atractivos para la práctica de deportes de montaña como la escalada, alpinismo, ciclismo de montaña o Trail running.

En relación a la climatología, son los contrastes climáticos el rasgo más importante, la pluviometría puede alcanzar una media superior a los $650 \mathrm{~mm} / \mathrm{año} / \mathrm{m}^{2}$ en las zonas de montaña respecto a los llanos de $360 \mathrm{~mm} / \mathrm{año} / \mathrm{m}^{2}$, existen notables desajustes entre espacios áridos y frondosos, con una media anual de 90 días de precipitación de los que unos 15 corresponden a días de nevadas. La media anual es de $15,2^{\circ}$, aunque los contrastes entre invierno y verano pueden oscilar, veranos son cortos, muy caliente y mayormente 
despejados; los inviernos son largos, fríos, ventosos y parcialmente. Durante el transcurso del año, la temperatura generalmente varía de $1{ }^{\circ} \mathrm{C}$ a $34{ }^{\circ} \mathrm{C}$ y rara vez baja a menos de -3 ${ }^{\circ} \mathrm{C}$ o sube a más de $37^{\circ} \mathrm{C}$. Clasificándose el clima según la escala de Köppen como de estepa local (BKk)

Desde el punto administrativo, el amplio municipio de Moratalla está compuesto por el núcleo principal que reúne el $70 \%$ de la población frente al $30 \%$ que estaría diseminado en un total de once pedanías que a su vez se dividen en otras entidades menores o pequeñas aldeas algunas en estado de abandono poblacional muy severo

Figura 2. Topografía e hidrografía del término municipal de Moratalla

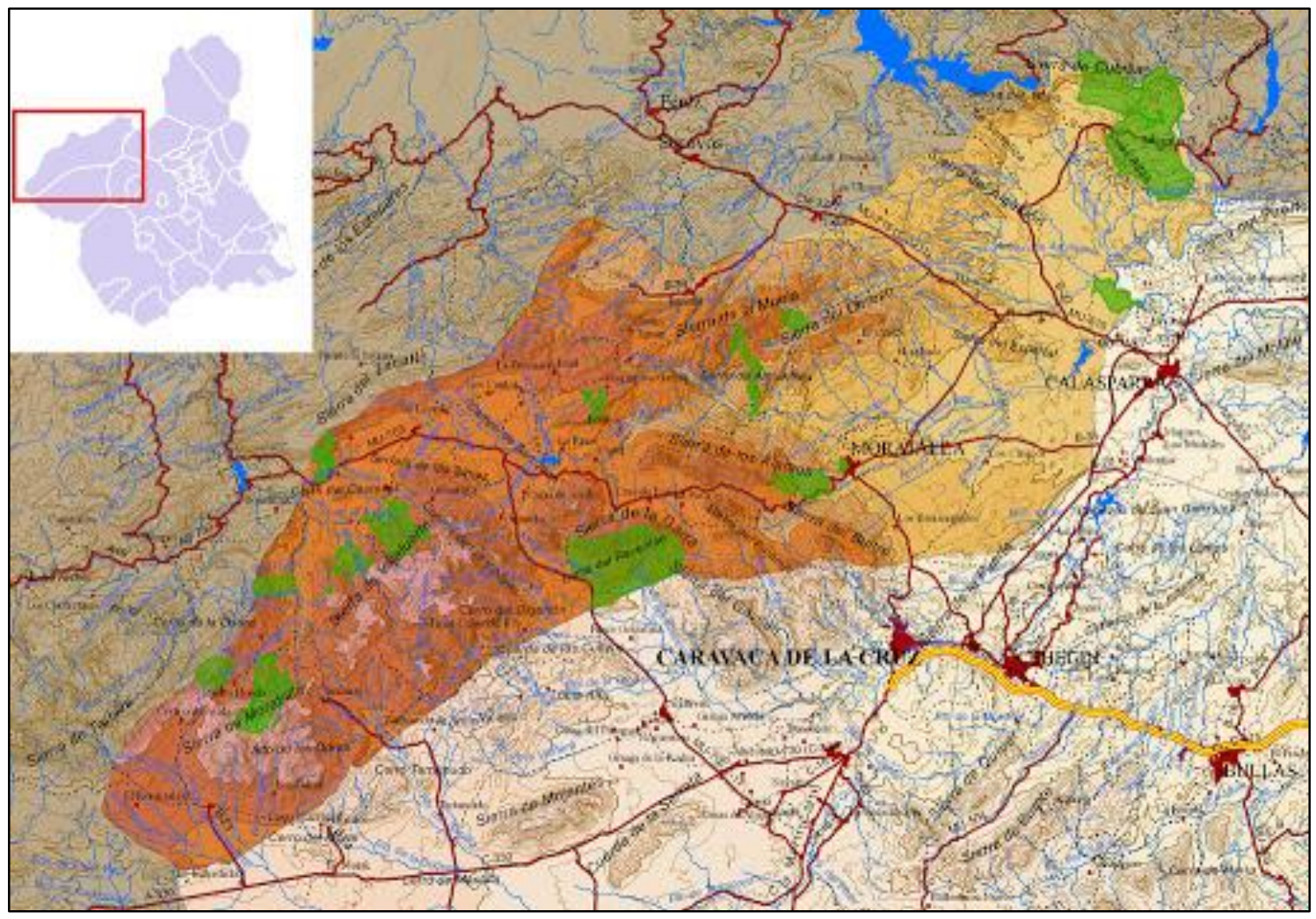

Fuente: http://www.murcianatural.carm.es/alfresco/service/montes/municipio?q=30028\&guest=true

Moratalla se integra en el conjunto de municipios que componen el NO de Murcia, compuesto por un total de cinco: Bullas, Calasparra, Caravaca de la Cruz, Cehegín y Moratalla, con una densidad media de $30,33 \mathrm{hab} /$ por $\mathrm{km}^{2}$, lo que significa unos datos muy bajos en relación a la media nacional $(92,3)$ y autonómica $(130,7)$. Desde los años 50 del pasado siglo XX este espacio ha experimentado una continua pérdida de población en los espacios de mayor altitud topográfica, y por tanto, un mayor aislamiento poblacional (Cebrián, 2007). No obstante, el municipio que presenta de forma destacada un importante vaciamiento demográfico es el de Moratalla, ya que, con una media de 8,3 $\mathrm{hab} / \mathrm{km}^{2}$ presenta un grave riesgo de desaparición como núcleo poblacional del interior de la Región de Murcia (Moya y Marín, 2015) al igual que otros municipios limítrofes con este que pertenecen a las provincias de Albacete y Jaén o la España interior (Del Romero, 2018). 
Figura 3. Distribución de pedanías en el término y plano del casco urbano de Moratalla

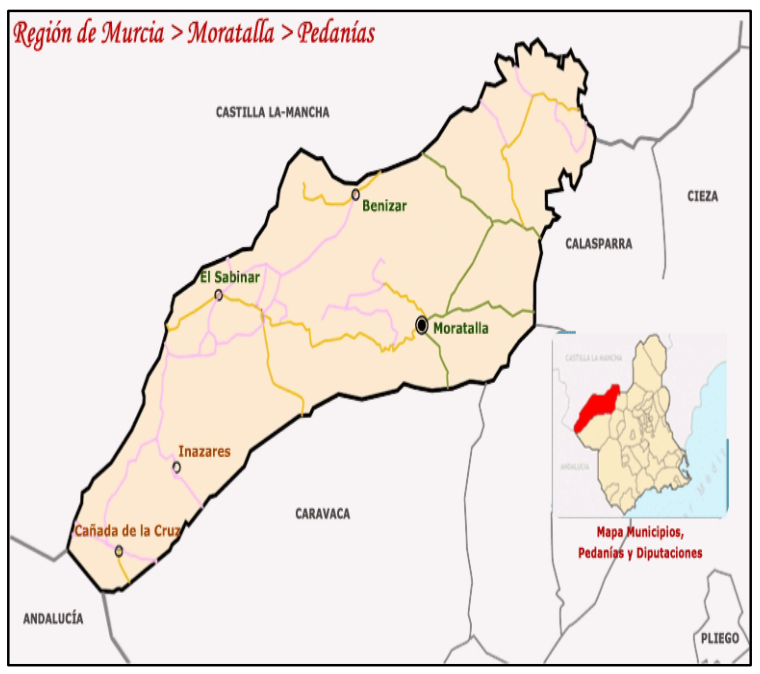

Fuente: https://www.regmurcia.com/servlet/s.Sl?sit=a,85,c,567,m,2140

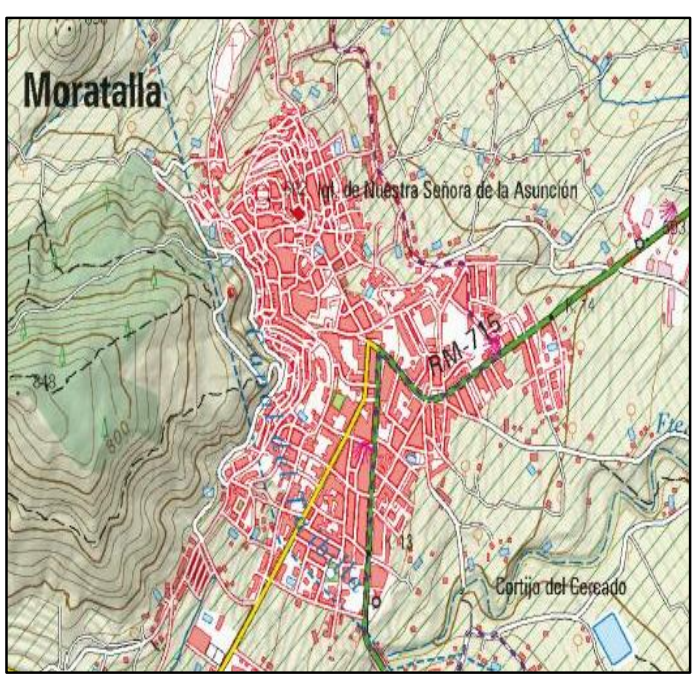

Fuente: PNOA Iberpix (2018)

En la Figura 4 presentada a continuación, se observa gráficamente la evolución poblacional de Moratalla, destacando el máximo poblacional alcanzado en el año 1950 con 14.536 habitantes, a partir de este dato se inició una progresiva pérdida demográfica que ha llegado a nuestros días y que continuará en el futuro según las previsiones de falta de natalidad y envejecimiento poblacional, así como la ausencia de inmigración que pudiera paliar esta debilidad respecto a los índices de fecundidad.

Figura 4. Evolución demográfica del municipio de Moratalla (1900-2019)

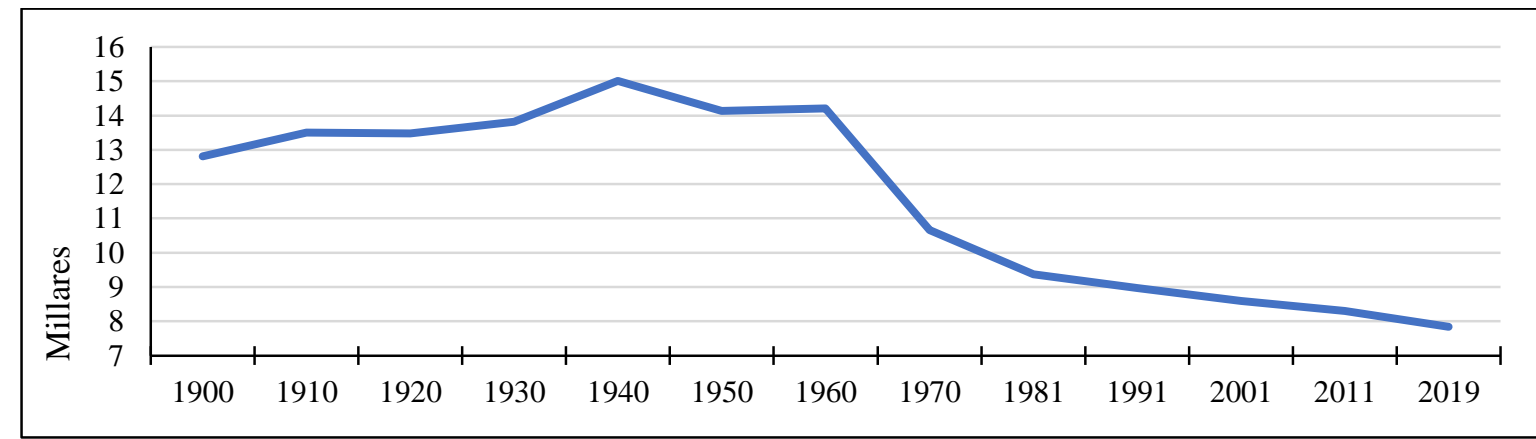

Fuente: INE y elaboración propia.

Anteriormente señalábamos la distribución territorial de Moratalla, compuesta por un municipio de grandes dimensiones con un núcleo principal y once pedanías. El estudio poblacional determina la preocupante pérdida de población, no solamente en el casco urbano de Moratalla, también todas las pedanías han experimentado un gran retroceso como se observa en la Tabla 3, en donde quedan contrastados los datos del máximo poblacional en 1950 y la realidad actual. El municipio ha perdido desde su máximo en 1950 al tiempo actual un total de 6190 habitantes, lo que supone el $44 \%$ de la población.

En su conjunto el casco de Moratalla ha perdido desde 1950 a 2019 un total de 751 habitantes, lo que supone un 11,4 2\%, mientras que el dato más relevante sería para el conjunto de las pedanías que han pasado de los 7.364 habitantes (más que el casco urbano) 
a los 1935 lo que supone el 88,58 \% de la población total perdida, ello significa un importante deterioro en las pedanías, donde la mayor parte de las personas jóvenes en edad de trabajar han abandonado estas tierras para marcharse fuera del municipio a otros lugares donde las posibilidades de trabajo o estudio son mayores. Entre las pedanías más afectadas por este abandono poblacional destacamos el caso de Rogativa que pierde el 97,47 \%, Benamor el 96,56 \% y Arenal el 95,92\% de sus efectivos, mientras que las menos perjudicadas por este éxodo son: Benizar que ha perdido el 32,95\% y Campo de San Juan con un $70,03 \%$.

Tabla 1. Distribución del número de habitantes en Moratalla y sus pedanías (1950-2019)

\begin{tabular}{|l|c|c|}
\hline & 1950 & 2019 \\
\hline Arenal & 589 & 4 \\
\hline Benamor & 116 & 855 \\
\hline Benizar & 1.275 & 150 \\
\hline Cañada de la Cruz & 1.002 & 14 \\
\hline Cobatillas & 547 & 21 \\
\hline Inazares & 287 & 34 \\
\hline Roble & 501 & 8 \\
\hline Rogativa & 316 & 15 \\
\hline Río Segura-Salmerón- & 463 & 518 \\
\hline Sabinar -San Bartolomé- & 1.112 & 255 \\
\hline San Juan & 871 & 32 \\
\hline San Pedro de Bejar & 285 & 5.904 \\
\hline Núcleo urbano de Moratalla y huerta Alharabe & 6.665 & 7.839 \\
\hline Total & 14.029 & 4 \\
\hline
\end{tabular}

Fuente: padrón municipal.

Moratalla dentro de su ámbito comarcal presenta un comportamiento distinto a los otros cuatro municipios, son significativos los datos que aparecen en la Figura 5, mientras que Moratalla ha perdido un 38,22 \% de su población total entre los años 1900 a 2019, los demás siempre han ganado población, Caravaca un 62,56 \%; Bullas un 59,65\%; Calasparra un 57,99 \% y Cehegín un 29,15 \% (Figura 5).

Incluso el propio casco urbano de Moratalla este abandono poblacional está repercutiendo en un importante deterioro en las calles más intrincadas de la parte alta debido entre otras causas al difícil acceso de vehículos de cuatro ruedas, falta de actividad comercial, envejecimiento del parque inmobiliario que es menos confortable o un nuevo estilo de vida que valora más la existencia de patios, parcelas o espacios para el aparcamiento. En el año 1950 eran 6.665 las personas que habitaban el núcleo urbano de Moratalla, actualmente son 5.904 y son muchas las familias han decido vivir en los nuevos barrios de acceso llano o en el espacio periurbano, se trata de la huerta de Alharabe que cuenta con 402 habitantes que se deberían restar del núcleo principal quedando por tanto el mismo en 5.502 habitantes, por tanto mientras en casco antiguo se vacía progresivamente 
los barrios nuevos reciben esa población, este crecimiento de la ciudad se ve reflejado en la Figura 6, donde se indica la evolución de la construcción por décadas.

Figura 5. Evolución poblacional de los municipios del NO murciano (1900-2019)

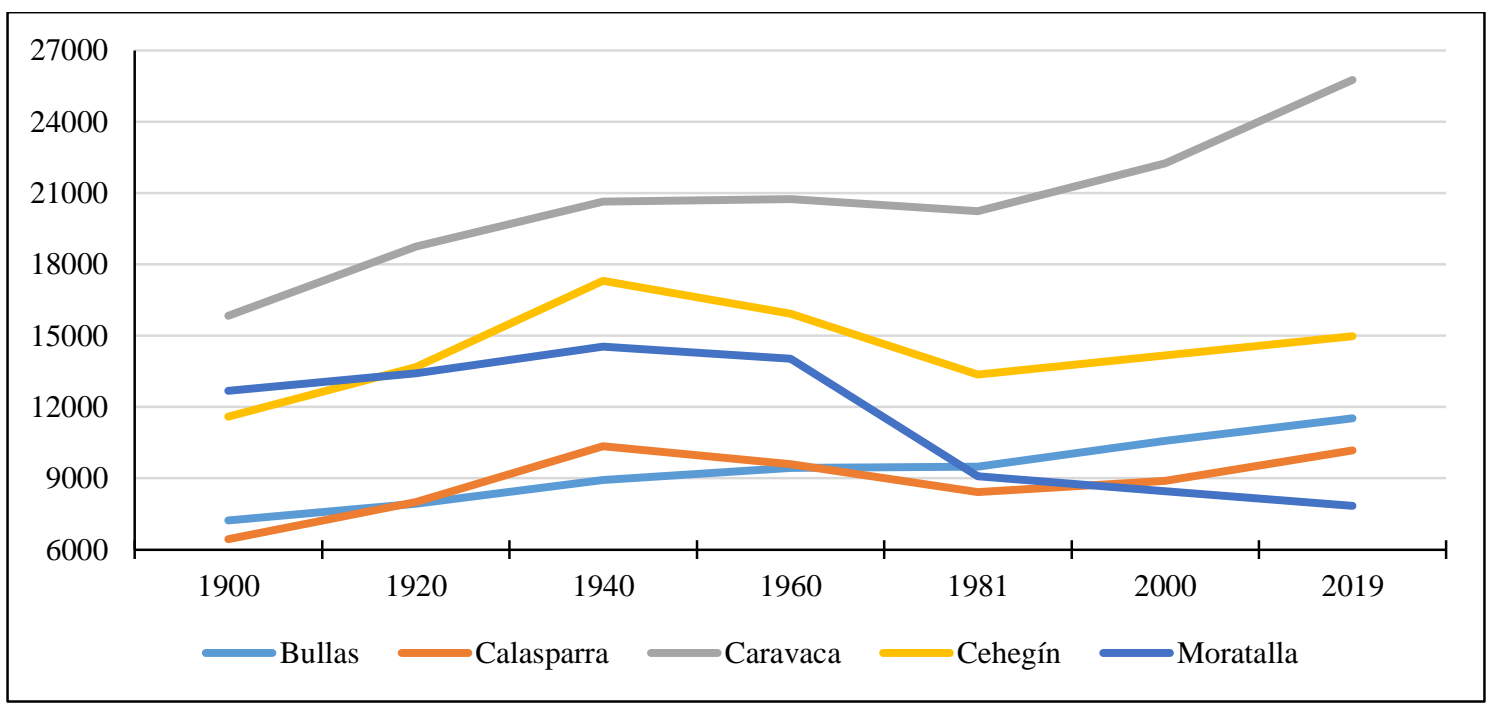

Fuente: INE.

Figura 6. Evolución de la edificación en Moratalla por décadas (1900-2019)

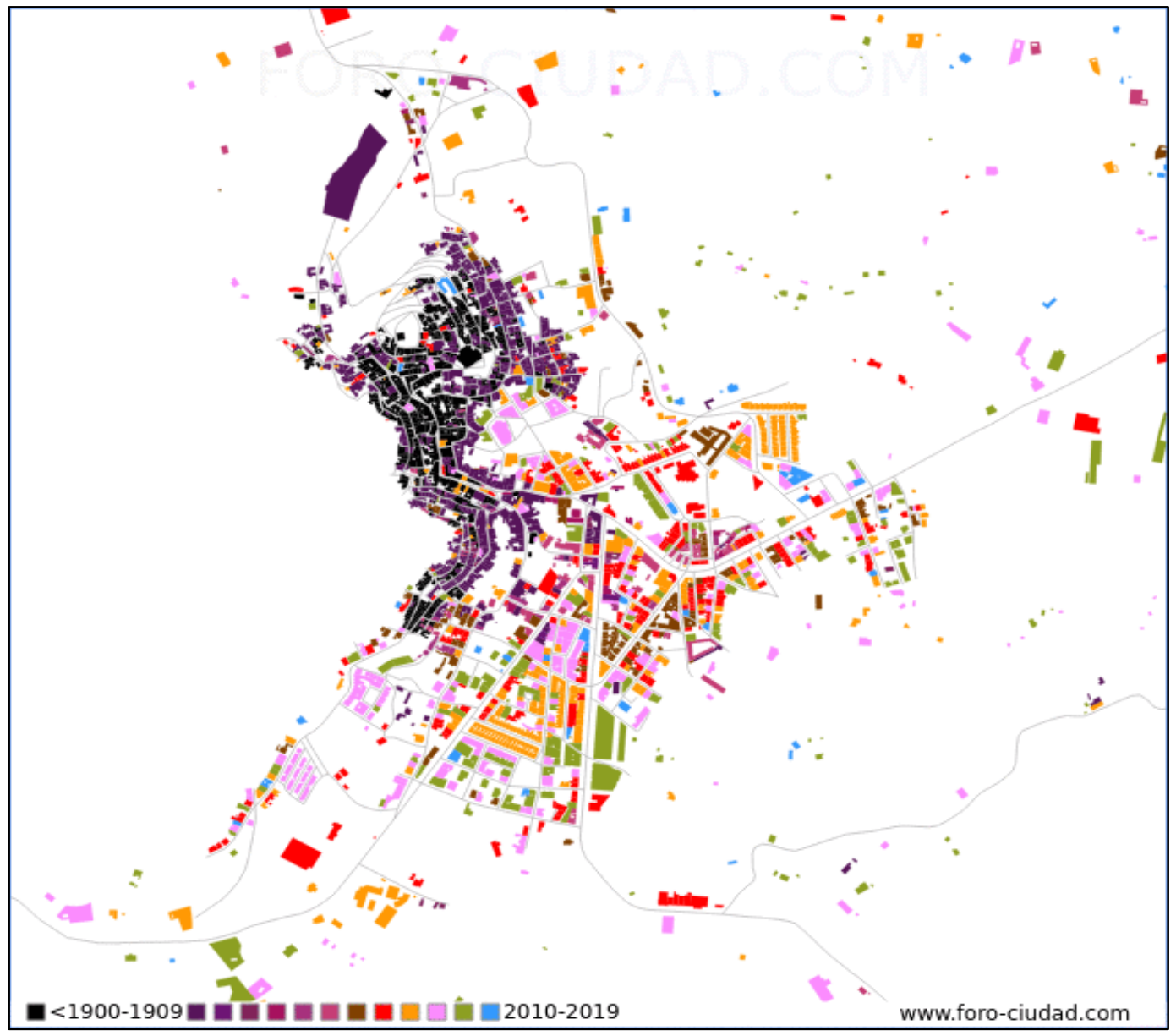

Fuente: https://www.foro-ciudad.com/murcia/moratalla/habitantes.html 
El casco antiguo, tal como se contempla en la Figura 7, presenta la estampa de una ciudad medieval, donde destacan el castillo-fortaleza, de tres plantas, con una magnifica torrehomenaje y declarado monumento nacional, a continuación, destaca la monumental iglesia de La Asunción, construida en el siglo XVI como muestra de estilo renacentista aunque ha sufrido debido a varios incendios reformas hasta llegar a la últimas intervenciones realizadas en el siglo XX.

Al tratarse de una ciudad histórica, encontramos la impronta dejada por otros edificios de gran identidad como son El convento de San Francisco construido en el siglo XVI sobre la antigua ermita de San Sebastián o la ermita de Santa Ana del siglo XVII. Dentro del término municipal también es destacable los restos árabes del castillo-atalaya de Benizar, la ermita de La Rogativa o la Casa del Cristo, donde se haya el centro de interpretación del arte rupestre de Moratalla.

Figura 7. Casco urbano de Moratalla
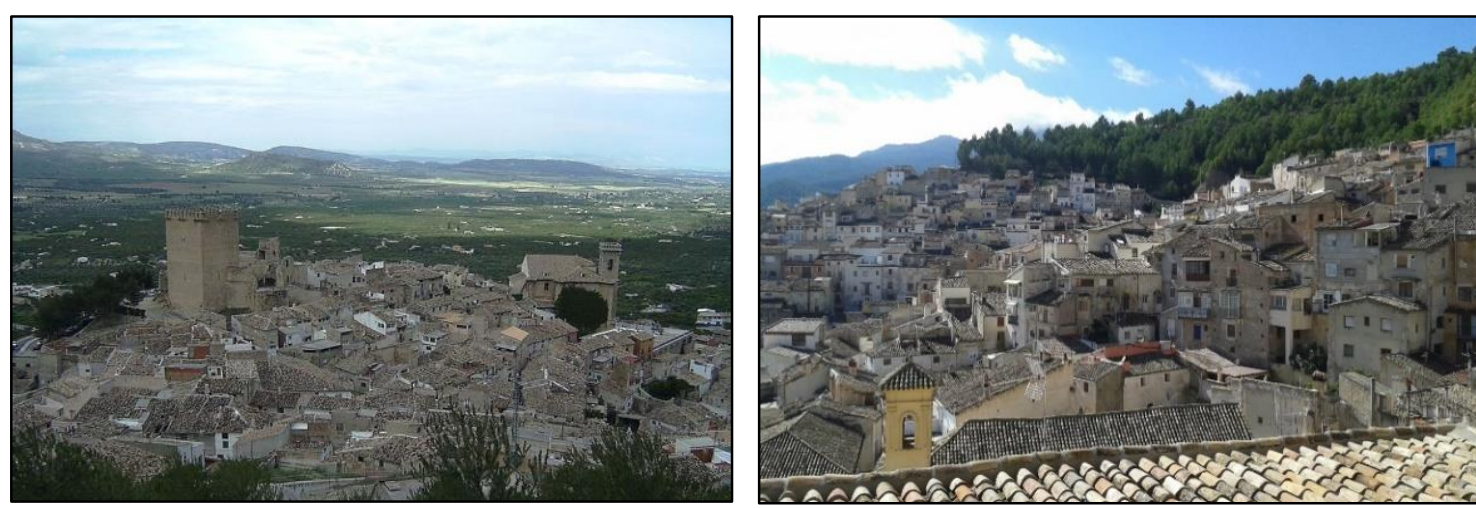

Fuente: autor.

Continuando con el aspecto demográfico, la Figura 8, contiene la pirámide de población de Moratalla y de la Región de Murcia, en la primera se representa gráficamente la evolución poblacional hacia un modelo de pirámide regresiva, con los grupos de edad de menos de 15 años recortados, de hecho, este grupo de edad de 0-14 significa un 12,34 \% frente al del grupo de mayores de 65 que se sitúa en un 22,7 \% del total de la población y el grupo medio (15-64 años) representaría un 64,96 \%, mientras que en la región de Murcia esa regresión es inferior y menos acusada que para el caso de Moratalla, de hecho los porcentajes regionales son diferentes, el grupo de edad de $0-15$ es un 16,91\%, el de $15-64$ de un 67,20 \% y mayores de 65 años alcanza el 15,89\%, seis puntos menos que Moratalla.

A nivel comarcal, también el dato de Moratalla en el grupo de edad de mayores de 65 años también es sensiblemente superior al resto de los otros cuatro municipios (Tabla 2), puesto que ninguno de ellos llega al $19 \%$, quedándose Calasparra en el 18,8 y Cehegín en el 18,7 como los más próximos a Moratalla. Mientras que en los grupos de edad de los jóvenes (0-14 años), Moratalla alcanza sólo el 12,34, mientras que los otros municipios están siempre por encima del $13 \%$, Cehegín tendría un 13,33 y el de mayor porcentaje sería Caravaca de la Cruz con un 15,46\%. No obstante los datos de Moratalla presentan diferencias con el resto España que alcanza un valor superior a todos ellos en el grupo de edad de mayores de 65 años, llegando al 19,58\%. 
Figura 8. Pirámides de población en el Municipio de Moratalla y Región de Murcia (2019)
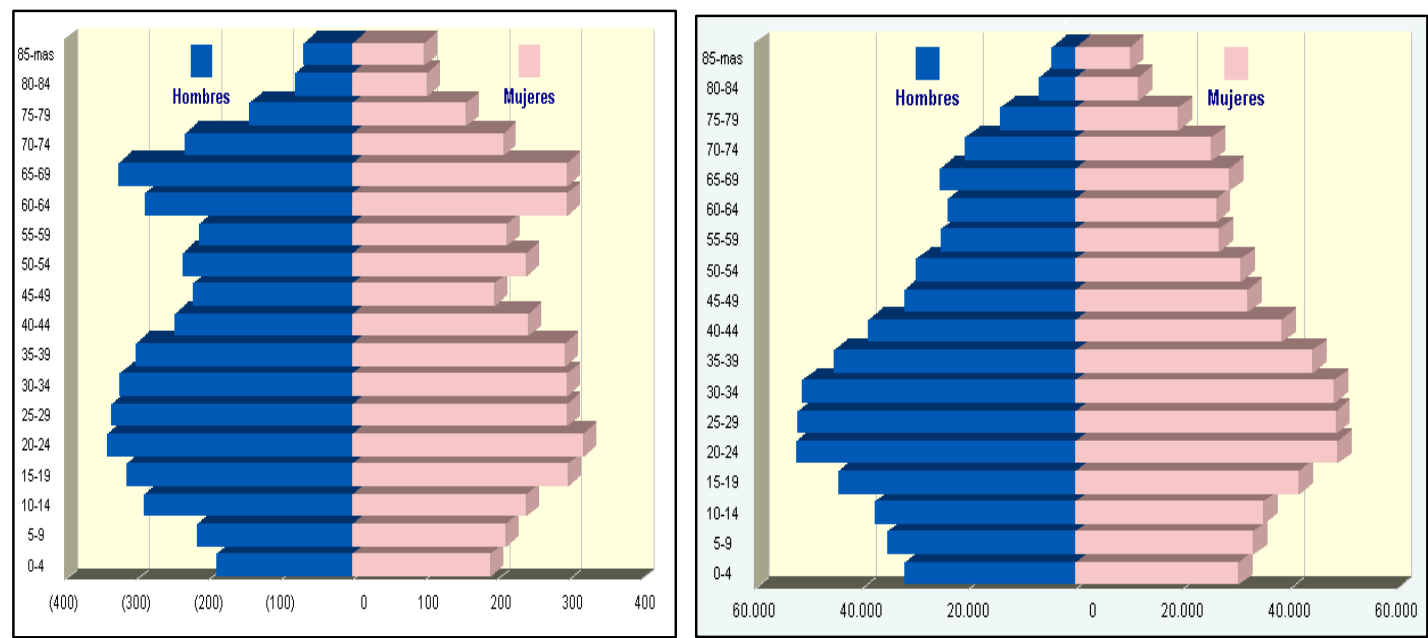

Fuente: Padrón municipal.

Tabla 2. Porcentaje por grupos de edad en \% de los municipios del NO, Reg. de Murcia y España

\begin{tabular}{|l|c|c|c|}
\hline & $0-14$ & $15-64$ & + de 65 años \\
\hline Bullas & 14.41 & 67.69 & 17.9 \\
\hline Calasparra & 14.22 & 66.98 & 18.8 \\
\hline Caravaca de la Cruz & 15.46 & 67.54 & 17.0 \\
\hline Cehegín & 13.33 & 67.64 & 18.7 \\
\hline Moratalla & $\mathbf{1 2 . 3 4}$ & $\mathbf{6 4 . 9 6}$ & $\mathbf{2 2 . 7}$ \\
\hline Región de Murcia & 16.91 & 67.20 & 15.89 \\
\hline España & 14.53 & 65.89 & 19.58 \\
\hline
\end{tabular}

Fuente: elaborado a partir de datos del INE.

Otro aspecto interesante es la tasa de natalidad y su relación con el envejecimiento poblacional de Moratalla. Aplicando la fórmula para hallar este índice obtenemos una tasa de 6,63 nacimientos por cada 1.000 habitantes, más baja que la tasa media española situada en un 7,6 y la de Murcia que es la más alta de España con un 9,51 a excepción de las ciudades autónomas de Ceuta y Melilla con un 9,90 y 14,77 según el INE. Se trata de un dato preocupante cuya tendencia al continuar proyectándose en el futuro asegura que el colapso demográfico está garantizado en esta ciudad, de hecho, el crecimiento vegetativo alcanza en lo que llevamos de siglo XXI, unas cifras muy significativas tal como se refleja en la Tabla 3.

Tabla 3. Evolución del crecimiento vegetativo en Moratalla durante el siglo XXI

\begin{tabular}{|l|l|l|l|}
\hline \multicolumn{1}{|c|}{ Año } & \multicolumn{1}{|c|}{ Nacimientos } & \multicolumn{1}{|c|}{ Defunciones } & \multicolumn{1}{|c|}{ Diferencial } \\
\hline 2001 & 82 & 73 & 1,66 \\
\hline 2005 & 71 & 94 & $-2,42$ \\
\hline 2010 & 72 & 84 & $-2,13$ \\
\hline 2015 & 75 & 102 & $-3,66$ \\
\hline 2018 & 53 & 111 & -7.04 \\
\hline
\end{tabular}

Fuente: INE. 
Otro indicador demográfico que nos ofrece una visión de la estructura poblacional sería el índice de envejecimiento que expresa la relación entre la cantidad de personas adultas mayores y la cantidad de niños y jóvenes, calculando el cociente entre personas de 65 años y más con respecto a las personas menores de 15 años, multiplicado por 100, para el caso de Moratalla obtendríamos:

$$
\text { Ienv }=\frac{\mathrm{P}^{1} 65 \mathrm{y} \text { más }}{\mathrm{P}^{1}} \times 100
$$

Lo que arrojaría para el año 2019, el dato de un índice de 23,82 personas de 65 o más años respecto al total de la población, dato muy distante de la Región de Murcia que muestra un 15,62 y de España con un 19,25.

En relación a la movilidad de la población debida a los movimientos migratorios, el análisis de datos corrobora un porcentaje de población extranjera en el municipio de Moratalla del 4,35 \%, un dato bajo en relación a Murcia que alcanza el 14,1 \% o España del 12,9 \% en el año 2019; respecto a la nacionalidad por continentes en Moratalla en primer lugar serían los procedentes de África con un 49,56 \%, a continuación de Europa, $34,6 \%$, de América un 10,56 \% y finalmente Asia que alcanza el 3,51\%. En todo caso la población inmigrante de Moratalla ha llegado básicamente para trabajar en la agricultura $\mathrm{y}$ en menor medida en los servicios.

La comarca del NO de Murcia, en la cual se encuentra Moratalla, está compuesta por cinco municipios que presentan una situación de estancamiento e incluso de retroceso demográfico, con la excepción de Caravaca de la Cruz que alcanzó su máximo demográfico en 2011 y luego ha tenido un decrecimiento leve hasta 2020. El éxodo rural con la llegada de la industrialización de España a partir del Plan de Estabilización de 1959, supuso el traslado de muchas personas a regiones con un gran desarrollo industrial como Valencia y Barcelona, a lo que se unió el efecto salida hacia Europa en esta década por el extraordinario desarrollo económico de países como Alemania, Francia o Suiza fueron los factores más significativos (Martínez, 1988).

La economía de Moratalla ha estado basada de forma ininterrumpida en el sector primario, la agricultura dedicada esencialmente a cultivos de secano como los cereales, el olivo y la almendra, así como a frutales de hueso como el melocotón, ciruela y albaricoque. Respecto a la ganadería destaca el ovino y porcino, en menor medida la explotación del bosque a través de la industria maderera y corcho, también aparecen industrias de alimentación derivadas de la propia materia prima existente, muebles, bebidas, textil y metálicas. En las últimas décadas ha aparecido el turismo rural como una modalidad complementaria que no ha terminado de consolidarse y dar los frutos esperados por las autoridades locales y la oficina de desarrollo local, aunque como más adelante veremos la potencialidad del territorio y paisaje levantan grandes expectativas en el desarrollo del turismo rural y de naturaleza. Por sectores de actividad comparando el municipio de Moratalla con la media regional se observa un mayor porcentaje de población empleada en el sector primario, mientras que en los servicios es sensiblemente más baja, lo que denota la especialización de Moratalla más en el Primario e Industrial que en tareas dedicadas a los servicios y comercio. 
Tabla 4. Porcentaje de empleo según sectores económicos Moratalla y total regional

\begin{tabular}{|c|c|c|c|c|}
\hline & Agricultura & Industria & Construcción & Servicios \\
\hline Moratalla & 13,86 & 24,93 & 6,49 & 54,48 \\
\hline Región Murcia & 9,37 & 14,74 & 12,98 & 62,32 \\
\hline
\end{tabular}

Fuente: elaborado a partir de datos de la CARM.

Respecto a las tasas de desempleo, Moratalla ocupa el número cuatro de la Región en cuanto de los datos más altos, como se puede ver en la Tabla 5, aparecen tanto municipios del litoral como del interior y con distintas especializaciones económicas.

Tabla 5. Tasa de mayor porcentaje de desempleo entre los 10 primeros municipios de Murcia

\begin{tabular}{|c|c|c|c|}
\hline Municipio & \% de desempleo & Municipio & $\%$ de desempleo \\
\hline 1. La Unión & 23,63 & 6. Alcantarilla & 20,8 \\
\hline 2. Albudeite & 23,37 & 7. San Pedro Pinatar & 20,3 \\
\hline 3. Cehegín & 22,25 & 8. Calasparra & 20,15 \\
\hline 4. Moratalla & $\mathbf{2 2 , 2 1}$ & 9. Fortuna & 19,6 \\
\hline 5. Ojos & 21,4 & 10. Cartagena & 19,49 \\
\hline
\end{tabular}

Fuente: https://datosmacro.expansion.com/paro/espana/municipios/murcia

En relación a la tasa desempleo a nivel comarcal, los cinco municipios tienen una tasa mayor $(18,19 \%)$ que la media nacional $(14,1 \%)$ y autonómica $(14,2 \%)$, también respecto a la renta media disponible la comarca presenta una media de 13.989 frente a los 14.467 de la comarca y los $17.905 €$ de media regional.

Tabla 6. Características más importantes de los municipios de NO de Murcia (2019)

\begin{tabular}{|c|c|c|c|c|c|c|}
\hline Municipio & Habitantes & $\begin{array}{c}\mathrm{km}^{2} \text { del } \\
\text { término }\end{array}$ & $\begin{array}{c}\text { Densidad } \\
\text { hab/km }{ }^{2}\end{array}$ & $\begin{array}{c}\text { \% de desempleo } \\
\text { (diciembre) }\end{array}$ & $\begin{array}{c}\text { Renta media } \\
\text { disponible }(€)\end{array}$ & $\begin{array}{c}\text { Plazas } \\
\text { hoteleras }\end{array}$ \\
\hline Bullas & 11.547 & 82,2 & 140,50 & 17,23 & 14.275 & 65 \\
\hline Calasparra & 1.0165 & 184,9 & 55,00 & 18,33 & 14.228 & 21 \\
\hline Caravaca & 25.730 & 858,7 & 29,90 & 15,21 & 16.259 & 212 \\
\hline Cehegín & 15.022 & 292,7 & 50,20 & 19,61 & 14.682 & 76 \\
\hline Moratalla & $\mathbf{7 . 9 5 4}$ & $\mathbf{9 5 4 , 8}$ & $\mathbf{8 , 3}$ & $\mathbf{2 0 , 5 8}$ & $\mathbf{1 2 . 8 5 3}$ & $\mathbf{3 6}$ \\
\hline
\end{tabular}

Fuente: elaborado a partir de datos de la CARM.

\section{BASES TEÓRICAS-CONCEPTUALES}

Las zonas escasamente pobladas y regiones con baja densidad de población suponen un importante desafío en la sociedad actual y ha sido motivo de un importante debate dentro del seno de la Unión Europea (1991 y 2011). España es un buen ejemplo en el contraste que suponen las altas densidades poblacionales del litoral y el caso aislado de Madrid junto a varias ciudades de interior que ejercen la capitalidad autonómica, como es el caso de Zaragoza o Valladolid, frente al vaciamiento demográfico experimentado en la mayor 
parte de la meseta, Extremadura, Aragón (Del Romero y Varela, 2013) o áreas de montaña. El modelo territorial español ha ido agudizando desde la segunda mitad del siglo XX el abandono de las áreas rurales de interior para ir aumentado los espacios de litoral (García-Moreno, 2019). La industrialización, el turismo y el desarrollo de las comunicaciones, así como los hábitos de vida urbano han sido factores decisivos en el aumento de desequilibrios socioeconómicos que lejos de mejorarse se están acentuando en un mundo globalizado en donde el desarrollo local representa una estrategia diferente pero con un importante contribución al desarrollo global (Fuertes y Gatica, 2008).

Las regiones de la España vaciada/despoblada padecen una serie de problemas estructurales que constituyen un gran reto, experimentan una fecundidad muy baja, huida de las personas jóvenes que se marchan en busca de mejores condiciones de vida, envejecimiento demográfico, falta de empleos y carencias en servicios básicos como la educación, sanidad o acceso a las nuevas tecnologías de la comunicación.

Esparcia (2008), señala que el despoblamiento en buena parte de las áreas rurales españolas es un fenómeno probablemente irreversible, en crisis desde hace varias décadas por estar incorporado al sistema agropecuario tradicional, sin haberse producido el necesario cambio de mentalidad para abordar los nuevos retos tecnológicos y una mejora sustancial en las comunicaciones y la conectividad entre el campo y ciudad. La revitalización social del medio rural (Guinjoan et al., 2016) supone la participación del capital social existente en proyectos liderados por entidades supranacionales tales como la Unión Europa, los planes como LEADER se constituyen en elementos dinamizadores que pueden detener la sangría demográfica y potenciar los recursos económicos de estos espacios, también cobran importancia las iniciativas destinadas al descubrimiento del medio rural como espacio de ocio y descanso enfocado hacia el turismo de naturaleza, son elementos esenciales para revertir los procesos de abandono (Jurado y Pazos, 2016)

El desarrollo territorial según el Banco de desarrollo de América Latina, se apoya al menos en cuatro pilares básicos: el primero sería el desarrollo humano que posibilita la mejora de la educación, el empleo, la incorporación de la mujer y un trabajo dignificado; tiene por tanto una importante dimensión en las personas y la relación con su formación para el desempeño de sus tareas (García y Malarín, 2011). El segundo pilar se enfocaría hacia el desarrollo social e institucional a través de la participación ciudadana, la creación de redes locales y el fomento de los gobiernos locales, en este sentido es importante el desarrollo de grupos de acción social vinculados al territorio, en este sentido las autoridades locales, los agentes de desarrollo local tienen una función primordial. En tercer lugar, el avance hacia la sostenibilidad de este medio con la valorización del medio ambiente, el fomento de las energías renovables, la evaluación del impacto ambiental y la incorporación de hábitos de vida involucrados en la propia naturaleza. Finalmente, como cuarto pilar, hablaríamos de desarrollo económico local, con la creación de infraestructuras y equipamientos básicos, apoyo a los trabajadores autónomos, existencia de créditos y ayudas económicos asumibles, un sistema fiscal admisible y la posibilidad de que las iniciativas emprendedoras pudieran desarrollarse sin grandes trabas administrativas, este apartado supone la existencia de mecanismos donde los habitantes de estos núcleos puedan recibir soporte administrativo y acceso a la capitalización de los negocios o posibles emprendimientos.

La gestión del desarrollo local se ha constituido en un nuevo paradigma en el conjunto de la ordenación territorial (Noguera et al., 2009), teniendo como eje fundamental la distribución social del progreso y bienestar, realidades que apuntan directamente a la implementación de políticas y estrategias de desarrollo regional. En las últimas décadas hemos asistido al nacimiento de movimientos vecinales como: Soria o Teruel existe, 
incluso en junio de 2020 asistimos a la constitución en el Congreso de los Diputados, sin ningún voto en contra del primer pacto de estado por la España Vaciada, así como manifiestos importantes como el realizado por la Asociación de Española de Geografía $(\mathrm{AGE})^{1} \mathrm{o}$ en contextos europeos ante las políticas de cohesión para hacer frente al cambio demográfico ${ }^{2}$.

Figura 9. Dimensiones del Desarrollo Territorial
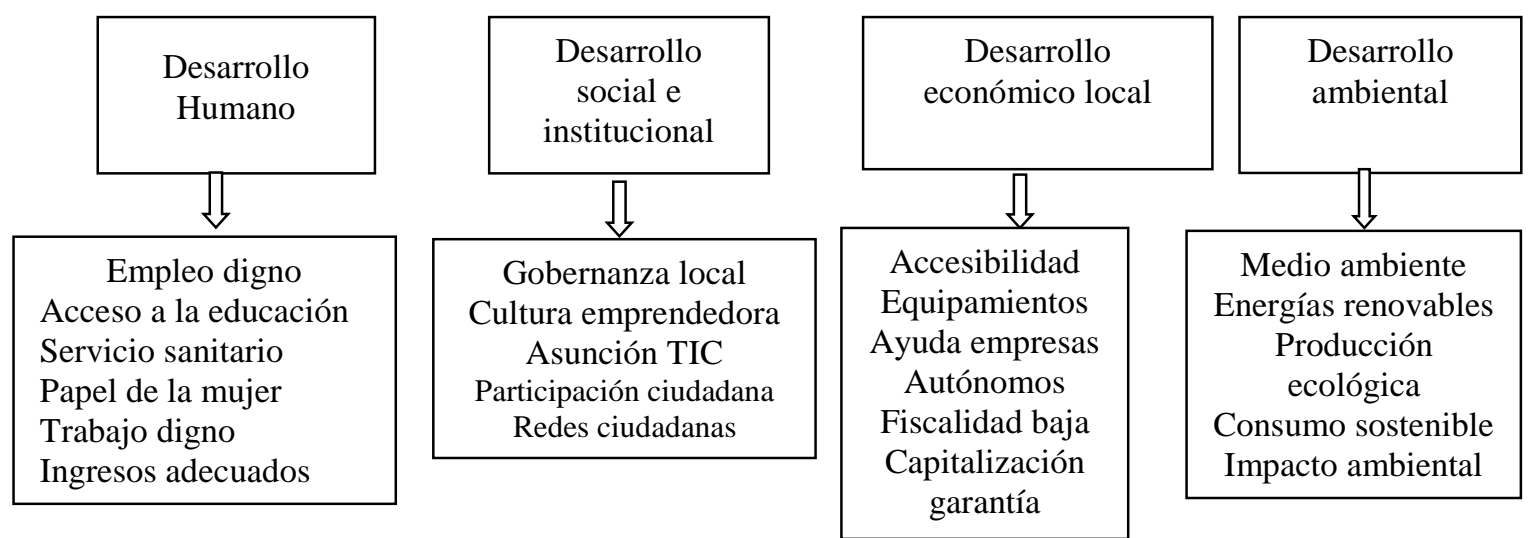

Fuente: elaboración propia

\section{OBJETIVOS, METODOLOGÍA Y FUENTES}

Este artículo aborda un tema de gran actualidad como es el proceso de vaciamiento demográfico de un municipio de interior localizado en la Región de Murcia, dentro de la denominada comarca del NO murciano, compuesta por los municipios de Bullas, Calasparra, Caravaca, Cehegín y Moratalla. Espacios con parecidas condiciones físicas, climáticas sociodemográficas, aunque con matizaciones en su generalizada pérdida de efectivos demográficos desde hace varias décadas. A través de una base estadística cuya fuente principal es el INE y CARM (2020) se investiga sobre la situación demográfica actual y las perspectivas de futuro, también el análisis cualitativo que ofrece la herramienta DAFO se efectúa una aproximación a las debilidades y fortalezas así como las amenazas y oportunidades existentes que condicionan o permiten la evolución demográfica de este municipio y las repercusiones en el desarrollo económico y territorial de esta espacio enclavada en el interior de la Región de Murcia (Ortín y Cano, 2013).

El análisis DAFO es un instrumento eficaz para el análisis de estudio de la situación de una empresa o un proyecto, analizando sus características internas (debilidades y fortalezas) y su situación externa (amenazas y oportunidades) en una matriz cuadrada (Morales, 2018). También es una herramienta para conocer la situación real en que se encuentra una organización, empresa o proyecto, y planear una estrategia de futuro, permitiendo la participación de distintos grupos de interés, ya que los participantes en las entrevistas son expertos o conocedores de la investigación llevada a cabo, lo que indica suficientes garantías de fiabilidad en las respuestas, y ello se incrementa cuando las respuestas llegan a un índice de saturación alto (por encima del $90 \%$ de coincidencias). De la combinación de fortalezas con oportunidades surgen las potencialidades, las cuales

\footnotetext{
${ }^{1} \mathrm{https}: / /$ www.age-geografia.es/site/manifiesto-despoblacion/

2 https://www.europarl.europa.eu/doceo/document/A-8-2017-0329_ES.pdf?redirect
} 
señalan las líneas de acción más prometedoras para la organización. Las limitaciones, determinadas por una combinación de debilidades y amenazas, colocan una seria advertencia (Tabla 7) e invitan a la puesta en marcha de acciones que mejoren las perspectivas poco satisfactorias.

Tabla 7. Matriz DAFO

\begin{tabular}{|c|c|c|}
\hline Fortalezas & $\begin{array}{c}\text { Oportunidades } \\
\text { ¿Qué oportunidades externas pueden ser } \\
\text { aprovechadas por las fortalezas internas? }\end{array}$ & $\begin{array}{c}\text { AQué amenazas externas pueden ser } \\
\text { contrarrestadas por las fortalezas internas? }\end{array}$ \\
\hline Debilidades & $\begin{array}{c}\text { ¿Qué oportunidades externas pueden ser } \\
\text { aprovechas si se superan las debilidades } \\
\text { internas? }\end{array}$ & $\begin{array}{c}\text { ¿Qué amenazas externas no pueden ser } \\
\text { contrarrestadas si no se superan las } \\
\text { debilidades internas }\end{array}$ \\
\hline
\end{tabular}

Fuente: Espejo (2013).

Una vez finalizados los análisis parciales (definidos los objetivos sobre el que se desarrolla el estudio y la realización del trabajo de campo para conocer la realidad sobre la que se acomete el análisis), éstos permitirán realizar un diagnóstico de las debilidades, amenazas, fortalezas y oportunidades para, a continuación, y en función de este análisis, establecer unos objetivos, proponer diferentes estrategias de desarrollo capaces de superar los condicionantes identificados y alcanzar los objetivos de conocimiento el fenómeno de la despoblación de este espacio geográfico y otras implicaciones en la salud y el desarrollo demográfico (Gómez et al., 2011).

Para la recogida de información se utilizó un criterio de selección de expertos basado en la elección de personas que conocen bien el espacio y los temas objeto de estudio. También se ha tenido en cuenta la accesibilidad y disponibilidad en sus centros de trabajo o actividades profesionales desarrolladas. Todas las personas seleccionadas cuentan con suficiente formación y gran experiencia lo que ha facilitado ampliamente nuestra tarea. A lo largo de las entrevistas, a través de un cuestionario semiestructurado pero abierto a matizaciones, se recogió la información de forma transversal, es decir, de una sola vez con el objetivo de estudiar fenómenos presentes en el momento de realización de la encuesta, lo que permitió un estudio tanto descriptivo como analítico, obteniendo estimaciones generales de las variables, comparaciones entre subgrupos y relaciones entre variables.

Las entrevistas fueron realizadas a representantes de los diversos colectivos de actores sociales, económicos y políticos de la comarca estudiada, lo que nos ha permitido disponer de una información cualitativa muy valiosa y representativa con relación a los objetivos que se pretendían alcanzar. Del mismo modo, se buscaron personas relacionadas con el entorno, que acumulaban experiencias y poseían opinión más que fundamentada sobre el tema objeto de investigación. Aunque los datos personales han sido eliminados por razones legales y de respeto, a cada encuesta se le asignó un código de forma que fuera posible identificar las opiniones de los participantes y de los colectivos a los que representaban de centro como el Ayuntamiento, asociación local de comercio, hostelería y turismo rural, profesores de enseñanza obligatoria, responsables de sindicatos y responsables políticos locales (Tabla 8). 
Tabla 8. Muestra seleccionada en las entrevistas

\begin{tabular}{|c|c|c|}
\hline Colectivo & $\mathrm{N}^{\circ}$ entrevistas & Código de colectivo \\
\hline Técnicos de Turismo y agentes de desarrollo local & 4 & TE1-TE4 \\
\hline Asociación casas rurales & 2 & ACR1- ACR2 \\
\hline Profesorado enseñanzas obligatorias & 4 & PROF1- PROF4 \\
\hline Miembros de Sindicatos actividad turística & 3 & SI1-SI2 \\
\hline Miembros de Patronales de Hostelería & 2 & PH1-PH2 \\
\hline Responsables de la Administración municipios & 4 & AD1-AD4 \\
\hline
\end{tabular}

Fuente: elaboración propia.

La metodología utilizada en esta investigación es inicialmente de tipo cualitativo siendo fundamental el diseño de una entrevista en profundidad. Se ha aplicado una técnica de triangulación estrechamente relacionada con la metodología cualitativa mediante dos procedimientos: la triangulación de fuentes, que permite contrastar la información obtenida por diversos procedimientos (cuestionarios, entrevistas, etc.); y la triangulación metodológica a través de la propia información reflejada en las entrevistas.

Tabla 9. Items y Preguntas para el desarrollo de entrevistas DAFO

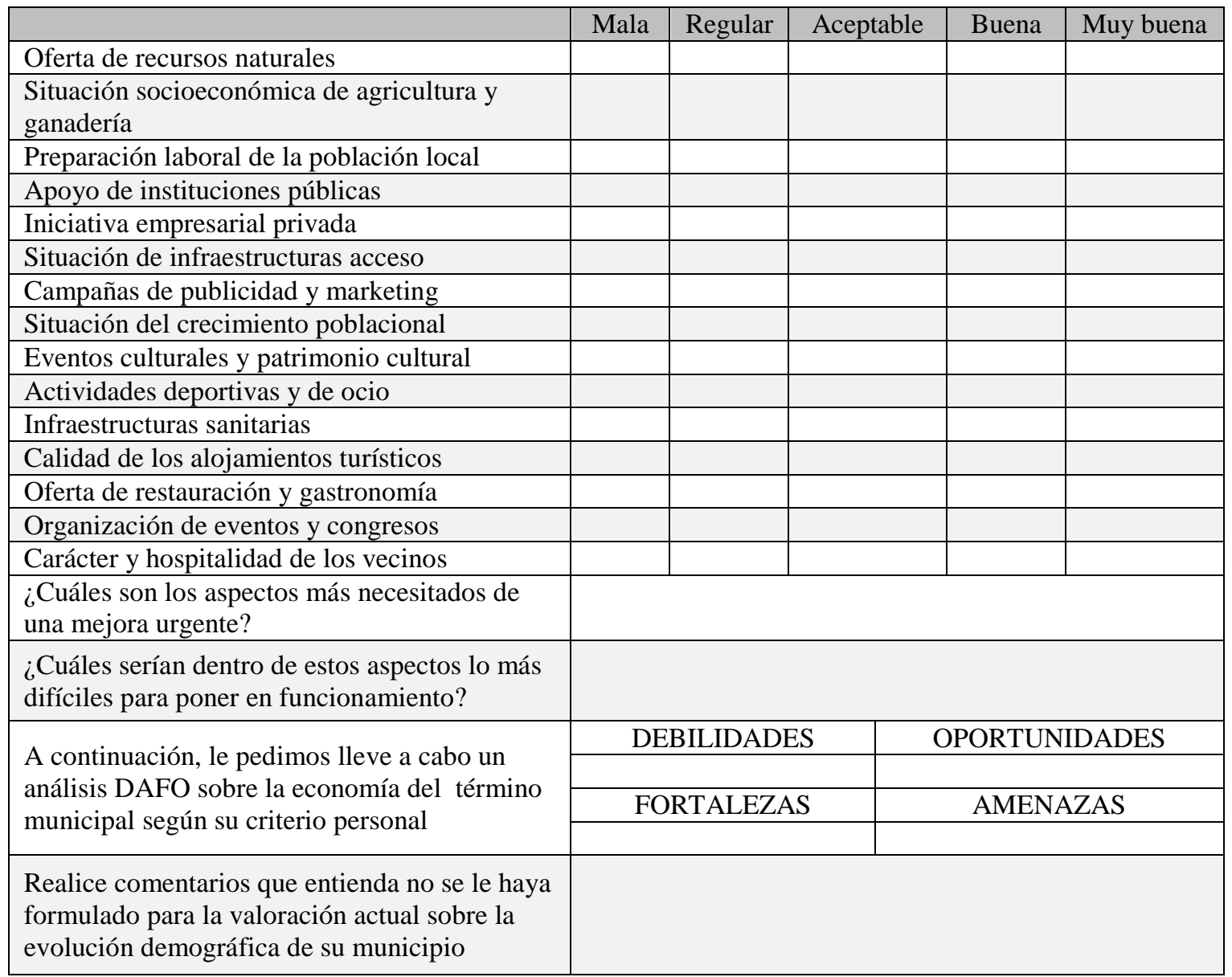

Fuente: elaboración propia. 
La muestra de informantes, su larga experiencia, amplia y larga trayectoria profesional, la variedad de responsabilidades desempeñadas les hace conocedores del sistema de organización del entorno socioeconómico del municipio. Estas características nos aseguran una información amplia y diversa, que, al proceder de fuentes variadas y complementarias, enriquecen la visión por nosotros pretendida, al igual que su diversidad en edades y funciones desempeñadas. Se presenta la matriz elaborada en la fase previa al propio análisis DAFO, que incluye lo que se han considerado puntos clave para abordar los procesos estudiados. Las preguntas han sido estructuradas en dos bloques: uno cerrado, constituido por cuestiones que debían ser respondidas por los entrevistados conforme a criterios de valoración de menos a más, y otro abierto, compuesto por cuatro preguntas de respuesta libre (Tabla 9).

\section{RESULTADOS}

Seguidamente, se muestran de forma sintética los resultados más destacados del análisis efectuado respecto al análisis DAFO interno (Tabla 10), la aparición de un total de dieciséis debilidades frente a doce fortalezas supone una importante descompensación en la capacidad de generación de actividad económicas y muy especialmente en la actividad turística que es viable en la Comarca (Cebrián, 2001).

Tabla 10. Análisis interno DAFO sobre vaciamiento demográfico en el municipio de Moratalla

\begin{tabular}{|c|c|}
\hline Debilidades & Fortalezas \\
\hline $\begin{array}{l}\text { 1. Renta baja en relación a media la Regional y } \\
\text { Nacional. } \\
\text { 2. Escasa presencia de industrias manufactureras. } \\
\text { 3. Poca expansión del sector servicios. } \\
\text { 4. No existe red ferroviaria, ni autovía } \\
\text { 5. Falta de conectividad en el eje: Caravaca- } \\
\text { Moratalla-Calasparra-Venta del olivo } \\
\text { 6. Espacio periférico a nivel Regional. } \\
\text { 7. Baja ocupación humana del territorio. } \\
\text { 8. Falta de coordinación intermunicipal a la hora } \\
\text { de mancomunar servicios colectivos. } \\
\text { 9. Escaso sector hostelero, no hay hoteles } \\
\text { 10. Poca capacidad de inversión y atracción de } \\
\text { capitales externos. } \\
\text { 11. Baja cualificación profesional. } \\
\text { 12. Rentas agrícolas bajas. } \\
\text { 13. Tasa de paro superior al resto de la CC.AA. } \\
\text { 14. Necesidad en la mejora de estudios } \\
\text { profesionales en F.P. } \\
\text { 15. Escasa promoción del gran patrimonio natural, } \\
\text { cultural e histórico de la comarca. } \\
\text { 16. Topografía complicada en parte del territorio. }\end{array}$ & $\begin{array}{l}\text { 1. Excelentes condiciones naturales para } \\
\text { promocionar el turismo rural. } \\
\text { 2. Patrimonio y paisaje cultural destacando la } \\
\text { ciudad Moratalla } \\
\text { 3. Existencia de rutas de gran interés turístico } \\
\text { por su singularidad. } \\
\text { 4. Oferta gastronómica variada. } \\
\text { 5. Situación geográfica como cruce de caminos } \\
\text { en el interior de Murcia hacia Albacete } \\
\text { 6. Posibilidad de diversificación de las actuales } \\
\text { actividades turísticas. } \\
\text { 7. Crecimiento de los mercados artesanales. } \\
\text { 8. Existencia de figuras como son los Agentes } \\
\text { de desarrollo local. } \\
\text { 9. Buenas condiciones para la elaboración de } \\
\text { productos de calidad y denominación de } \\
\text { origen. } \\
\text { 10. Espacio beneficiado por Fondos Europeos al } \\
\text { tratarse de una zona periférica }\end{array}$ \\
\hline
\end{tabular}

Fuente: elaboración propia.

El vaciamiento demográfico de Moratalla obedece a una dinámica generalizada en nuestro país desde la segunda mitad del siglo XX, según el Instituto Nacional de Estadística (INE) y la Federación Española de municipios (FEMP) existen 4.955 
municipios con menos de mil habitantes censados, y se considera que de los 8.131 un total 6.670 son rurales, lo que significa un porcentaje de un 82,03\%; en el caso de Moratalla, tal como muestra la herramienta DAFO se cumplen la mayor parte de las características que incorporan a este municipio como espacio en declive, necesitado de una fuerte intervención pública y privada para reconducir una situación extendida en el tiempo y con necesidad urgente de un cambio de rumbo que todavía podría ser reversible.

Respecto al análisis DAFO externo, en donde figuran amenazas y oportunidades, los resultados son los que se reseñan en la Tabla 11.

Tabla 11. Análisis externo DAFO sobre vaciamiento demográfico en la comarca del NO murciano

\begin{tabular}{|c|c|}
\hline & Oportunidades \\
\hline $\begin{array}{l}\text { 1. Es necesaria una continua remodelación del } \\
\text { patrimonio cultural en estado degradado en el } \\
\text { casco antiguo de Moratalla. } \\
\text { 2. Degradación de los elementos arquitectónicos } \\
\text { en las pedanías. } \\
\text { 3. Pérdida de población en todo el municipio y } \\
\text { muy grave en las pedanías. } \\
\text { 4. Falta en la mejora de competitividad ante la } \\
\text { adaptación al mundo empresarial. } \\
\text { 5. Inestabilidad laboral y precariedad en el } \\
\text { empleo. } \\
\text { 6. Crecimiento de otras comarcas de la Región en } \\
\text { detrimento de esta. } \\
\text { 7. La baja natalidad repercute en la creación de } \\
\text { servicios culturales. }\end{array}$ & $\begin{array}{l}\text { 1. Aprovechamiento de las campañas publicitarias } \\
\text { a nivel Regional. } \\
\text { 2. Posible conexión de autovía entre el cruce de la } \\
\text { Venta del Olivo (autovía desde Murcia a } \\
\text { Madrid) con Caravaca, faltaría la conexión con } \\
\text { Moratalla } \\
\text { 3. Demanda de actividades rurales y alojamientos } \\
\text { de este estilo } \\
\text { 4. Oportunidades vinculadas al desarrollo de la } \\
\text { TICs. } \\
\text { 5. Demanda de un modelo de turismo relacionado } \\
\text { con la cultura y arte. } \\
\text { 6. Equilibrio entre el patrimonio cultural y el } \\
\text { interés por la conservación medioambiental. } \\
\text { 7. Políticas de sostenibilidad ambiental y } \\
\text { paisajística. } \\
\text { 8. Iniciativas de cooperativismo en tareas } \\
\text { agrícolas. }\end{array}$ \\
\hline
\end{tabular}

Fuente: elaboración propia.

La actividad turística en Moratalla se presenta en este análisis DAFO como uno de los principales recursos que pueden favorecer la recuperación demográfica y económica de este espacio. La existencia de importantes recursos naturales, paisaje y elementos patrimoniales de un espacio histórico son elementos suficiente para hacer de Moratalla un lugar atractivo, de encuentro y preferencialidad para los interesados por el turismo rural, de interior, en donde las actividades deportivas en la naturaleza, el recorrido histórico por los monumentos ubicados esencialmente en el núcleo urbano u otros recursos como la artesanía, fiestas populares, museos, pinturas rupestres o una variada gastronomía son sus puntos fuertes.

El atractivo de los alojamientos rurales diseminados por el término municipal, es otra garantía para la capacidad de acogida, en las última tres décadas, Moratalla se ha convertido en el municipio que más plazas oferta en esta modalidad en toda la Comunidad Autónoma de Murcia y en la comarca de Nororeste, tal como figura en la Tabla 12.

Moratalla, es uno de los municipios que menores niveles de desarrollo presenta en la CC.AA., en base a indicadores convencionales como serían la renta per cápita, densidad de población, infraestructuras de comunicaciones, presupuesto municipal o capacidad de compra. Los desequilibrios existentes requieren de una profunda intervención tanto de la iniciativa pública como de la atracción para el sector privado que desemboquen en la 
creación de puestos de trabajo, evitando de esta manera la sangría demográfica desarrollada en el último medio siglo. El turismo es un sector estratégico, complementario a la tradicional economía rural y al mismo tiempo innovador ya que provoca la realización de nuevas obras, recuperación patrimonial y una nueva visión del territorio, que para el caso que nos ocupa está lleno de posibilidades y muy acorde con las nuevas tendencias del turismo actual reflejadas en una competitividad sostenible, inclusiva e innovadora (Cánoves et al., 2017).

Tabla 12. Equipamiento turístico del Noroeste de la CC.AA. de Murcia (2019)

\begin{tabular}{|c|c|c|c|c|c|c|c|c|c|c|}
\hline & \multicolumn{2}{|c|}{ Bullas } & \multicolumn{2}{c|}{ Calasparra } & \multicolumn{2}{c|}{ Caravaca } & \multicolumn{2}{c|}{ Cehegín } & \multicolumn{2}{c|}{ Moratalla } \\
\hline & \multicolumn{2}{|c|}{ Número/Plazas } & \multicolumn{2}{c|}{ Número/Plazas } & \multicolumn{2}{c|}{ Número/Plazas } & Número/Plazas & \multicolumn{2}{c|}{ Número/Plazas } \\
\hline Hoteles & 4 & 65 & 1 & 46 & 6 & 145 & 3 & 70 & $\mathbf{3}$ & $\mathbf{3 6}$ \\
\hline Casas Rurales & 20 & 99 & 8 & 51 & 86 & 530 & 30 & 170 & $\mathbf{1 6 8}$ & $\mathbf{1 . 0 1 4}$ \\
\hline Hospederías & 0 & 0 & 1 & 19 & 3 & 82 & 0 & 0 & $\mathbf{2}$ & $\mathbf{5 1}$ \\
\hline Apartamentos & 12 & 36 & 0 & 0 & 42 & 120 & 10 & 23 & $\mathbf{8}$ & $\mathbf{2 4}$ \\
\hline Restaurantes & 12 & 1.661 & 20 & 2.679 & 38 & 4.718 & 17 & 1.477 & $\mathbf{2 2}$ & $\mathbf{1 . 4 7 2}$ \\
\hline Cafeterías/bar & 5 & 23 & 8 & 322 & 6 & 111 & 5 & 127 & $\mathbf{4}$ & $\mathbf{6 2}$ \\
\hline
\end{tabular}

Fuente: CARM

\section{CONCLUSIONES}

El análisis de los datos indica desde el punto de vista de desarrollo humano que el municipio de Moratalla se encuentra en un proceso de regresión poblacional con una clara tendencia al envejecimiento, incapaz de tener un relevo generacional adecuado. Moratalla en el conjunto de los cinco municipios que componen la comarca del NO murciano presenta las cifras más elevadas en la evolución hacia el vaciamiento poblacional y este proceso continúa desarrollándose (Morales, 2020). Los otros cuatro municipios presentan una clara situación de estancamiento demográfico, excepto Caravaca que alcanzó su máximo demográfico en 2011 así como un desarrollo urbano destacado (Molina, 2002), aunque posteriormente ha tenido un decrecimiento poblacional leve hasta 2020, los otros tres municipios de la comarca: Bullas, Calasparra y Cehegín, presentan atenuados descensos desde la década de los 60 del siglo XX, cuando se inició el éxodo rural con la llegada de la industrialización de España y la emigración a diferentes países de Europa. Es notorio el caso de Moratalla que registra un índice de $8 \mathrm{Hab} / \mathrm{Km}^{2}$, mientras que los demás municipios también presentan bajos índices en relación a la media española $(92,3$ $\mathrm{Hab} / \mathrm{Km}^{2}$ ), Cehegín $18 \mathrm{Hab} / \mathrm{Km}^{2}$, Caravaca $15 \mathrm{Hab} / \mathrm{Km}^{2}$ o Calasparra $19 \mathrm{Hab} / \mathrm{Km}^{2}$; con la excepción de Bullas que posee un término municipal de una superficie muy pequeña $\left(82,2 \mathrm{Km}^{2}\right)$ y presenta una media de $140 \mathrm{Hab} / \mathrm{Km}^{2}$. Se precisa una mejora sustancial en la oferta educativa con la ampliación de ciclos formativos y la cualificación en general en la formación de la población. Los servicios sanitarios cubren las necesidades básicas de la población, aunque en las pedanías la grave pérdida de la población hace que los servicios asistenciales vayan decayendo, el centro hospitalario de referencia es el hospital comarcal de Caravaca (14 km), los casos más graves deben acudir a la capital murciana que se encuentra a $84 \mathrm{~km}$.

Entre los aspectos económicos más relevantes que presenta el análisis DAFO e inciden sobre el proceso de vaciamiento demográfico en Moratalla destacamos un sector primario poco renovado, debilidad de las conexiones intramunicipales, falta de incentivos para nuevas actividades económicas como podría ser el turismo o la necesaria en 
equipamientos y tecnología en las empresas, se precisa el incremento de ayudas para la financiación de autónomos y unas medidas fiscales que favorezcan y atraigan nuevas inversiones foráneas. También, Espejo (2002) señala la escasez de tejido industrial como un factor decisivo, a lo que debemos sumar un mayor desarrollo del sector terciario, en concreto el comercio y el turismo permanente a lo largo del año.

En relación a las fortalezas que potencialmente ayudarían al desarrollo económico, destacamos el importante patrimonio natural y cultural (Zárate, 2016), la concienciación de las entidades locales a través de los agentes de desarrollo local del necesario esfuerzo que se debe hacer para salir de esta situación de estancamiento socioeconómico del municipio que se aleja de la media comarcal y regional tanto en el aspecto demográfico como en el nivel de renta por habitante. Respecto al análisis DAFO externo, observamos como amenazas más destacadas, el avance en la pérdida de efectos demográficos en todo el municipio debida por un lado a la baja natalidad y la emigración de los grupos de edad más jóvenes que buscan su promoción personal fuera de la comarca, emigrando a la capital regional y a otros lugares de España y del extranjero, este hecho es la causa principal que acentúa el progresivo envejecimiento y el abandono de las pedanías que componen parte de la estructura comarcal, en el municipio de Moratalla con un total de once pedanías y una treinta de aldeas es donde más población se ha perdido (el $87 \%$ ), incluso algunas de ellas está a punto de llegar al cero en efectivos. Destacamos la falta de competitividad en relación a otras comarcas de la Región de Murcia.

Respecto a las oportunidades que se vislumbran son significativas el crecimiento del turismo rural y naturaleza, la implementación de las TIC que puedan exportar las bondades de este espacio como recurso turístico, así como la producción de artesanía y productos ecológicos que ofrece la tierra.

El avance hacia la creación de fuentes de energía alternativas sostenibles como serían la eólica y solar, tampoco ha tenido una especial incidencia en el término municipal debido entre otras causas a la falta de inversiones de capital foráneo y la necesaria accesibilidad a los lugares donde se deberían llevar a cabo estas instalaciones, esta actividad junto a las tradicionales y el turismo, podría ser otra fuente en la creación de empleo que procurarían los anclajes necesarios para fijar población, así como la necesidad de fomentar hélices de empleo que ofrezcan perspectiva de futuro para una población joven cada vez más escasa y con menos sentimiento de identidad, que a la menor oportunidad sale del término para volver de forma esporádica y con cierto desarraigo muy difícil de recuperar.

\section{ORIENTACIONES}

El municipio de Moratalla es un claro ejemplo de vaciamiento demográfico y pérdida de actividad económica dentro del interior de la Región de Murcia, la falta de una actividad económica rentable, diversificación de la empleabilidad, falta de incentivos o debilidad de las comunicaciones son algunos de los factores que han determinado esta situación que avanza irremediablemente y genera un futuro para este municipio complicado en su desarrollo territorial y poblacional. Desde este trabajo y tras el análisis CAME como una metodología suplementaria a la del Análisis DAFO practicado, se recomendaría implementar iniciativas que puedan frenar las amenazas existentes, contrarrestar las debilidades existentes, potenciar las fortalezas acumuladas y avanzar hacia las escasas oportunidades existentes. 
Se recomienda desde nuestra visión personal, la búsqueda de políticas activas de empleo, fomentado la ayuda a la iniciativa privada apoyada en el sector primario, la especialización agrícola, mejora en la actividad ganadera y mecanización son elementos básicos que pueden ayudar a la aparición de una industria casi inexistente de productos agrícolas y ganaderos. La artesanía necesita una mayor promoción en mercados nacionales e internacionales. La silvicultura representa una enorme importancia que debe centrarse en la sostenibilidad del bosque y su promoción como espacio de naturaleza.

El casco antiguo de Moratalla representa un espacio de singular belleza que avanza hacia la degradación y el abandono de viviendas, urgen políticas y medidas de revitalización patrimonial a través de fondos europeos, estatales, autonómicos y locales. La conservación de este paisaje urbano exigiría la contratación de muchos puestos de trabajo para una posterior proyección como enclave turístico singular.

Figura 10. Enclave singular del Castillo e Iglesia de la Asunción en Moratalla
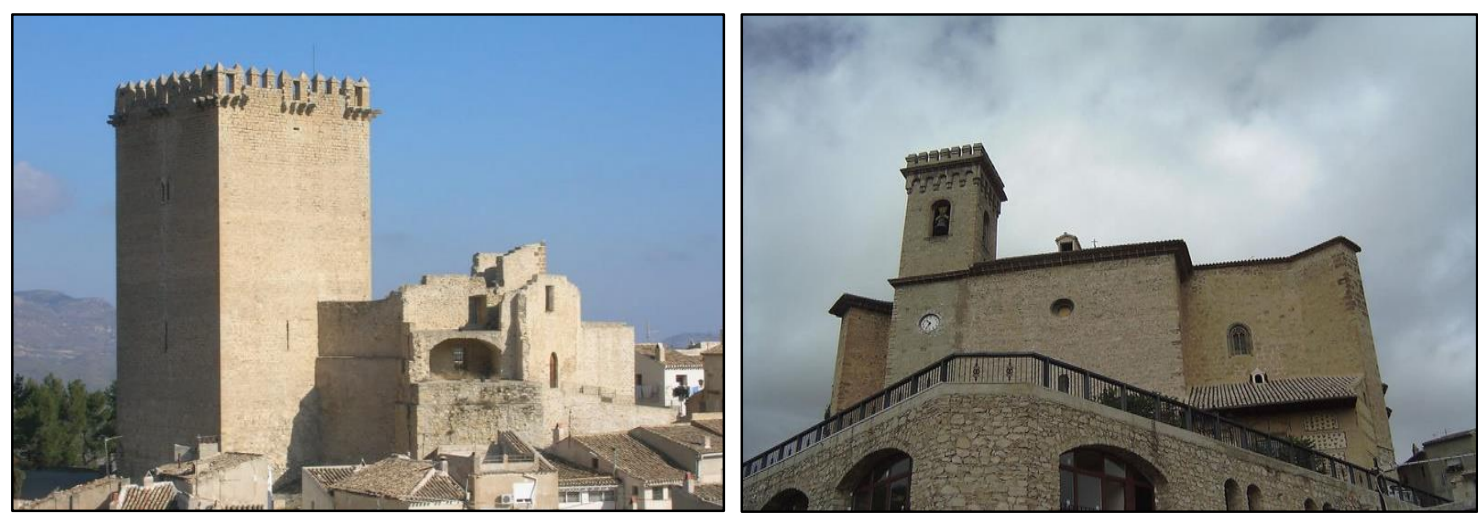

Fuente: autor.

El desarrollo local de Moratalla y municipio requieren de un gran esfuerzo colectivo entre administraciones públicas e iniciativas privadas, tal como señalan Pike et al. (2011), el desarrollo local debe ser una de las actividades más importante de los gobiernos locales. En este caso el Ayuntamiento de Moratalla ha lanzado a través de la oficina de desarrollo interesantes iniciativas turísticas potenciando las fiestas singulares, gastronomía y alojamientos rurales que permiten aprovechar el paisaje y los recursos que ofrece la naturaleza puesto que se detecta un aumento en el interés por las actividades de ocio al aire libre y la contemplación del paisaje (Mata, 2004), intentado reinventar el medio rural como un espacio de sosiego que no puede ofrecer la ciudad, de hecho hemos observado como la situación sanitaria provocada por la pandemia del COVID-19 ha repercutido en una visión del medio rural como un lugar más seguro y de acogida para el turismo familiar o un carácter menos masificado que otras modalidades tradicionales, por tanto la irreversibilidad de este proceso de pérdida poblacional podría tener solución si en los próximos años se posibilita el crecimiento y estimulo de la iniciativa privada al mismo tiempo que la administración es capaz de mejorar infraestructuras necesarias como las comunicaciones y el acceso a las TIC, así como una promoción sin precedentes del turismo de interior y la búsqueda de rentabilidad de los sectores tradicionales.

Tanto Moratalla como la comarca, es un espacio de gran valor medioambiental, con escasos impactos medioambientales, es un territorio donde es posible el cumplimiento de los objetivos y metas promovidos por la ONU a través de los Objetivos de Desarrollo Sostenibles (ODS) dentro de la agenda 2030, como la existencia de una red de agua limpia 
y saneamiento efectiva (6), la promoción de energía asequible y no contaminante (7), la ciudad y sus núcleo sostenible (11), producción y consumo responsable (12), la búsqueda de una disminución de los efectos del cambio climático (13) o el mantenimiento de vida en los ecosistemas terrestres (15) existentes a lo largo del amplio término municipal con prácticas agrícolas adaptadas, ganadería extensiva o tratamiento del bosque son excelentes ejemplos.

Finalmente habría que motivar mucho más la participación ciudadana en los procesos de conocimiento y toma de decisiones estratégicas, las iniciativas de asociaciones o incluso la creación de una fundación para la recuperación patrimonial e integral de Moratalla y su término municipal podrían favorecer los procesos de envejecimiento poblacional y deterioro económico, así como la mejora de capacidad de respuesta ante los retos presentes y futuro al que se verá sometido este singular territorio.

\section{REFERENCIAS BIBLIOGRÁFICAS}

Banco de Desarrollo de América Latina (2013). Recuperado de: https://www.caf.com/es/actualidad/noticias/2013/07/4-pilares-para-el-desarrollosostenible/ (28/12/2020).

Cánoves, G., de Uña, E., y Villarino, M. (2017). Turismo de interior en España. Productos y dinámicas territoriales. Universidad de Valencia.

CARM (Centro Estadístico de la Región de Murcia) (2020). Recuperado de: $<$ http://econet.carm.es/municipios-en-cifras> (23/02/2020).

Cebrián, A. (2001). Los proyectos de turismo cultural sostenible en Lorca y Caravaca de la Cruz (Murcia), en A. Cebrián (coord.), Turismo cultural y desarrollo sostenible. Análisis de áreas patrimoniales Murcia, (pp. 315-334), Universidad de Murcia.

Cebrián, A. (2007). El Noroeste de Murcia, en Atlas global de la Región de Murcia, (pp. 404-407), La Verdad.

Conesa, C. (Ed). (2006). El medio físico en la Región de Murcia. Universidad de Murcia.

Del Romero, L. (2018). Despoblación y abandono de la España rural. El imposible vencido. Tirant Lo Blanch.

Del Romero, L., y Valera, A. (2013). Territorios abandonados. Paisajes olvidados de Teruel. Rolde de Estudios Aragoneses.

Esparcia, J. (2008). Sistema de núcleos y gestión del territorio: del proceso histórico de desarticulación a los retos de futuro, en II Coloquio Hábitat disperso y desarrollo rural, (pp. 39-72), Rolde de Estudios Aragoneses y Asociación de Desarrollo del Maestrazgo.

Espejo, C. (2013). La configuración territorial en la comarca del NO, en G. Cánoves et al., Turismo de interior: renovarse o morir, (pp. 80-95), Universidad de Valencia.

Espejo. C. (2002). La industria en el Noroeste de la Región de Murcia. Evolución urbana y actividad económica en los núcleos históricos. Historia y Geografía del urbanismo. 
Fuertes, A. M., y Gatica, L. (2008). De la economía global al desarrollo local. El alcance de la intervención de los agentes de empleo y desarrollo local. Universidad de Valencia.

García, A., y Malarín, A. (2011). El desarrollo rural frente al despoblamiento de los pequeños municipios. Universidad de Almería.

García-Moreno, F. (2019). La despoblación del mundo rural. Aranzadi.

Gómez, R., et al. (2011). Salud, demografía y sociedad en la población anciana. Alianza Editorial.

Guinjoan, E., Badia, A., y Tulla, A. (2016). El nuevo paradigma del desarrollo rural. Reflexión teórica y reconceptualización a través de la rural web. Boletín de la Asociación de Geógrafos Españoles, (71), 179-204. DOI:10.21138/bage.2279.

Jurado, J. M., y Pazos, F. J. (2016). Población y turismo rural en territorios de baja densidad demográfica en España. Boletín de la Asociación de Geógrafos Españoles, (71), 247-272. DOI: 10.21138/bage.2282.

Martínez, J. (1988). Moratalla: su identidad física y humana. Tertulia cultural Hisn.

Mata, R. (2004). Agricultura, paisaje y gestión del territorio. Polígonos, (14), 97-137. Recuperado https://buleria.unileon.es/bitstream/handle/10612/8289/Agricultura.pdf?sequence= $1(11 / 07 / 2020)$.

Molina, A. L. (2002). Evolución urbana de Caravaca (S. XIII-1850), en Evolución urbana y actividades económicas en los núcleos históricos, (pp. 49-69), Grupo de investigación y Geografía del urbanismo de la Universidad de Murcia.

Morales, F. J. (2018). Caravaca de la Cruz (Murcia): Paisaje y patrimonio al servicio de un turismo cultural y religioso en desarrollo. Boletín de Real Sociedad Geográfica, (CLIII), 201-234. Recuperado de: <http://www.boletinrsg.com/index.php/boletinrsg/issue/view/4 (20/09/2020).

Morales, F. J. (2020). El Noroeste de Murcia: ¿una comarca en proceso de despoblación?. Polígonos, (32), 31-43. Recuperado de: http://revpubli.unileon.es/ojs/index.php/poligonos/article/view/6403/4925 $(18 / 10 / 2020)$.

Moya, C., y Marín, R. (2015). Envejecimiento de la población en la Región de Murcia: causas y consecuencias. Papeles de Geografía, (61), 44-59. doi:http://dx.doi.org/10.6018/geografia/2015/213901

Noguera, J., Pitarch, M. D., y Esparcia, J. (2009). Gestión y promoción del desarrollo local. Universidad de Valencia.

Ortín, J., y Cano, G. (2013). Territorio, población y vivienda en la Región de Murcia 2001-2011. Papeles de Geografía, (57-58), 209-223 (consulta 9/09/2020).

Pike, A., Rodríguez-Pose, A., y Tomaney, J. (2011). Desarrollo local y regional. Universidad de Valencia.

Unión Europea (1999). Estrategia territorial Europea. Recuperado de: https://ec.europa.eu/regional_policy/sources/docoffic/official/reports/pdf/sum_es. pdf $(13 / 09 / 2020)$. 
Unión Europea (2011). Agenda Territorial 2020 - Hacia una Europa integradora, inteligente $y$ sostenible de regiones diversas. Recuperado de: https://gerenciaurbanismo.cuenca.es/portals/gerenciaurbanismo/documents/Agend a_Territorial_Europea\%202020.pdf (13/09/2020).

Zárate, M. A. (2016). Paisajes culturales urbanos, oportunidad para la conservación del patrimonio y el turismo sostenible. Estudios Geográficos, 77(281), 693-728. https://doi.org/10.3989/estgeogr.201624. 